\title{
Linear programming and pediatric dietetics
}

\author{
BY CIRO COLAVITA \\ Pediatric Division, S. Paolo Hospital, Naples 80122, Italy \\ AND RENATO D'ORSI \\ Polytecnic, University of Naples, Naples 80122, Italy
}

(Received 23 November 1989 - Accepted 14 April 1990)

\begin{abstract}
The composition of $\mathbf{5 0 0}$ foods has been stored in a computer in order to analyse a child's diet. The methodology of operations research is applied to a very simple problem : a diet with only two foods. The geometrical representation of the 'feasible region' and of the 'objective function' is illustrated. One of the analytical methods employable with many variables (foods) is considered. This method was used in trying to find diets allowing for the preferential use of selected foods while respecting recommended dietary allowances, the tastes of the child and other constraints. The theoretical difficulty of transferring this methodology to pediatric dietetics was examined. We solved a simple case utilizing this procedure.

Linear programming and dietetics: Computer-aided dietetics
\end{abstract}

The content in $\mathrm{g}$ of the constituents of 500 foods commonly used in Europe have been expressed per $100 \mathrm{~g}$ edible portion in accordance with current literature (Paul \& Southgate, 1978; Fidanza \& Liguori, 1984; Luke, 1984), and have been stored in a computer. The contents of proteins, carbohydrates, lipids, saturated and polyunsaturated fatty acids, cholesterol, sodium, potassium, calcium, phosphorus and iron have been placed in this archive. Other information regarding the presence of milk protein and of gluten, the type of carbohydrates, and the age-dependent minimal and maximal helpings has also been included. A computer program, whose principal menu is shown in Table 1, permits the handling of this information and the compilation of the diet.

Table 1. Main menu

\begin{tabular}{|c|c|c|}
\hline & Paediatric Dietetics & Main menu \\
\hline A. & Food composition & \\
\hline B. & Patient data & \\
\hline C. & Diet input & \\
\hline D. & Display & \\
\hline E. & Modifications & \\
\hline $\mathrm{F}$. & Analysis & \\
\hline G. & Personalizations & \\
\hline $\mathrm{H}$. & Linear programming & \\
\hline I. & Printing & \\
\hline L. & Exit & \\
\hline \multicolumn{3}{|c|}{ Select option } \\
\hline
\end{tabular}

A, food's data base interrogation; B, patient's anagraphic data input; C, patient's diet input; D, patient's diet display (see Table 2); E, patient's diet manipulation; F, analysis of the diet (see Table 3); G, choice allowing the modification of the maximal and minimal helpings and the assignment of a score to the selected foods; $\mathrm{H}$, linear programming option; I, printing options. 
Table 2. A sample diet

\begin{tabular}{|c|c|c|}
\hline & Food & Amount ( $\mathrm{g}$ or $\mathrm{ml}$ ) \\
\hline \multirow[t]{5}{*}{ Breakfast } & Milk & 100 \\
\hline & Sugar & 15 \\
\hline & White bread & 20 \\
\hline & Jam & 15 \\
\hline & Butter & 10 \\
\hline \multirow[t]{7}{*}{ Lunch } & Pasta & 40 \\
\hline & Tomatoes & 80 \\
\hline & Olive oil & 5 \\
\hline & Sole & 50 \\
\hline & Olive oil & 10 \\
\hline & White bread & 40 \\
\hline & Oranges & 150 \\
\hline \multirow[t]{2}{*}{ Snack } & White bread & 30 \\
\hline & Butter & 10 \\
\hline \multirow[t]{3}{*}{ Dinner } & Pizza & 100 \\
\hline & Bacon & 30 \\
\hline & White bread & 20 \\
\hline
\end{tabular}

Table 3. Analysis of the diet in Table 2

(Name Micòl F, age 10 years, weight $30 \mathrm{~kg}$, height $1 \cdot 35 \mathrm{~m}$, energy intake recommended $7740 \mathrm{~kJ} / \mathrm{d}$ )

\begin{tabular}{|c|c|c|c|}
\hline \multirow[b]{2}{*}{ Energy $(\mathrm{kJ})$} & \multicolumn{3}{|c|}{$\begin{array}{l}\text { Recommended dietary } \\
\text { allowance }\end{array}$} \\
\hline & 5422 & $9623-10460$ & Low \\
\hline Protein ( $\%$ energy) & $0 \cdot 11$ & $0 \cdot 12-0 \cdot 15$ & Low \\
\hline Carbohydrate ( $\%$ energy) & 0.48 & $0.45-0.50$ & $\mathrm{OK}$ \\
\hline Fats $(\%$ energy) & 0.41 & $0.38-0.42$ & $\mathrm{OK}$ \\
\hline Cholesterol (mg) & 134 & $<300$ & $\mathrm{OK}$ \\
\hline Sodium (mg) & 1578 & $600-1800$ & OK \\
\hline Potassium (mg) & 993 & $1000-3000$ & Low \\
\hline Calcium (mg) & 379 & $700-900$ & Low \\
\hline Phosphorus (mg) & 509 & $700-900$ & Low \\
\hline Iron (mg) & $4 \cdot 4$ & $9-11$ & Low \\
\hline Polyunsaturated: saturated fats & $0 \cdot 25$ & $0 \cdot 9-1 \cdot 0$ & Low \\
\hline $\mathrm{Ca}: \mathrm{P}$ & 0.74 & $0 \cdot 9-1 \cdot 0$ & Low \\
\hline Breakfast (\% energy) & 0.22 & $0 \cdot 23-0.25$ & Low \\
\hline Lunch ( $\%$ energy) & $0 \cdot 34$ & $0 \cdot 28-0 \cdot 32$ & High \\
\hline Snack ( $\%$ energy) & $0 \cdot 11$ & $0 \cdot 13-0 \cdot 15$ & Low \\
\hline Dinner ( $\%$ energy) & 0.33 & $0.28-0.32$ & High \\
\hline
\end{tabular}

Table 2 illustrates a child's diet, as reported by the mother, or as suggested by the paediatrician. The composition of the diet, of course, can be analysed (see Table 3).

When the analysis shows marked deviations from requirements, an attempt at solving the problem is generally made by substituting some foods or choosing new helpings, or both. While the previously deviating components are now balanced, the new diet is often unbalanced with respect to other nutrients.

The paediatrician can, of course, use his or her experience, but might best rely on a new conceptual approach in trying to answer the following questions: "Is it possible to have diets for this child taking into account the constraints I have as a pediatrician at this moment such as the recommended dietary allowances (RDA) and the tastes of the child?' 


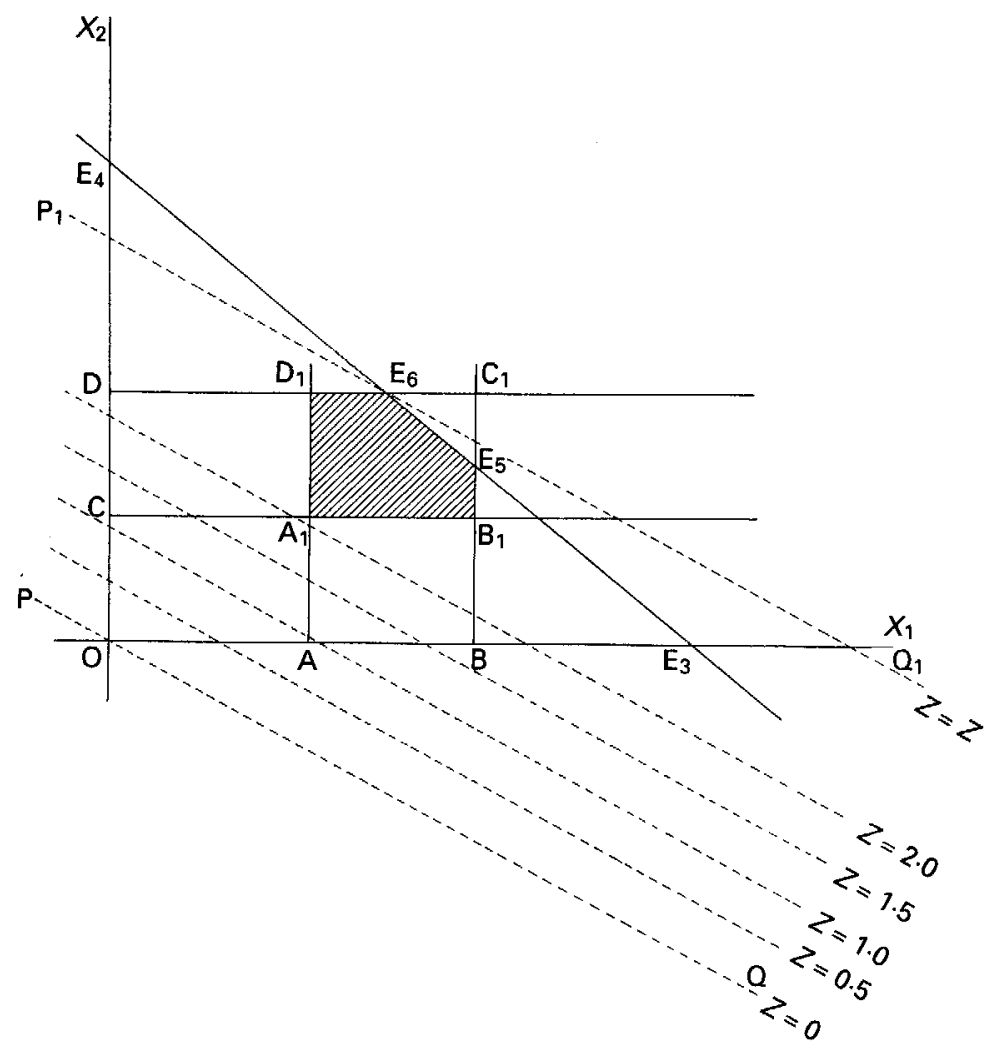

Fig. 1. The coordinates of the points located within the region delimited by the polygon $A_{1}, B_{1}, E_{5}, E_{6}, D_{1}$, the 'feasible region', correspond, in a simple diet with two foods $X_{1}$ and $X_{2}$ to helpings satisfying five constraints. A sheaf of parallel straight lines ( $Z$ lines) represent the 'objective function' to be maximized to obtain a 'high quality' diet.

'If such diets do exist, can I find the one diet that allows preferential use of the foods which are most useful to this child?'

In our experience it has been useful to use the methodology of operations research, which is a method used in problems of engineering, economics and management, to obtain an efficient allocation of scarce resources in order to identify the so-called optimal solutions. These solutions, in a specific context, correspond to the lowest cost or the maximal advantages and in general are the most convenient solutions from this point of view.

We may consider, for example, a very simple diet with only two foods (milk and meat) having weights $X_{1}$ and $X_{2}$. As it is mandatory to choose reasonable helpings appropriate to various age groups, it will be useful to respect the first four constraints, which could be

$$
\begin{array}{ll}
X_{1} \geqslant \mathrm{~A} ; & X_{1} \leqslant \mathrm{~B}, \\
X_{2} \geqslant \mathrm{C} ; & X_{2} \leqslant \mathrm{D},
\end{array}
$$

where $\mathrm{A}$ is milk, minimal helping; $\mathrm{B}$ is milk, maximal helping; $\mathrm{C}$ is meat, minimal helping; $\mathrm{D}$ is meat, maximal helping.

These constraints, plotted on a Cartesian plane (Fig. 1), locate a 'feasible region', a set of points satisfying the previously stated conditions. This region is delimited by the quadrilateral $\mathrm{A}_{1}, \mathrm{~B}_{1}, \mathrm{C}_{1}, \mathrm{D}_{1}$. 
A further constraint can be expressed as:

$$
\mathrm{E}_{1} X_{1}+\mathrm{E}_{2} X_{2} \leqslant \mathrm{E}
$$

where, for example $E_{1}$ is $g$ protein $/ 100 \mathrm{~g}$ milk, $E_{2}$ is g protein $/ 100 \mathrm{~g}$ meat, $E$ is maximal allowance of proteins $(\mathrm{g} / \mathrm{d})$. A constraint in form 1 can be represented by an equation adding a non-negative variable ( $S L$ in the example) which is the slack variable so that the relationship becomes

$$
\mathrm{E}_{1} X_{1}+\mathrm{E}_{2} X_{2}+S L=\mathrm{E} .
$$

The relationship $\mathrm{E}_{1} X_{1}+\mathrm{E}_{2} X_{2}=\mathrm{E}$ which derives from (1) with $S L=0, \mathrm{E}_{1}>0$ and $\mathrm{E}_{2}$ $>0$ corresponds on a graph to a straight line (Fig. 1) intersecting the abscissa $\left(X_{2}=0\right)$ at the point $\mathrm{E}_{3}$ with abscissa $X_{1}=\mathrm{E} / \mathrm{E}_{1}$ and the ordinate $\left(X_{1}=0\right)$ in the point $\mathrm{E}_{4}$ with ordinate $X_{2}=\mathrm{E} / \mathrm{E}_{2}$. As the constraint expressed by the relationship (1) is of the type $\leqslant$, the 'feasible region' is reduced to the polygon $A_{1}, B_{1}, E_{5}, E_{6}, D_{1}$. Additional constraints can either be ineffective or further reduce the region that satisfies all the constraints.

As a consequence, we shall have other type 1 relationships and in general a system such as the following:

$$
\begin{aligned}
& X_{1} \geqslant \mathrm{~A} \\
& \mathrm{X}_{1} \leqslant \mathrm{~B} \\
& \mathrm{X}_{2} \geqslant \mathrm{C} \\
& \mathrm{X}_{2} \leqslant \mathrm{D} \\
& \mathrm{E}_{1} X_{1}+\mathrm{E}_{2} X_{2} \leqslant \mathrm{E} \\
& \mathrm{F}_{1} X_{1}+\mathrm{F}_{2} X_{2} \leqslant \mathrm{~F} \\
& \quad \vdots \quad \vdots \\
& \mathrm{W}_{1} X_{1}+\mathrm{W}_{2} X_{2} \leqslant \mathrm{~W},
\end{aligned}
$$

where for example $E_{1}$ is $g$ protein $/ 100 \mathrm{~g}$ milk, $E_{2}$ is g protein $/ 100 \mathrm{~g}$ meat, $\mathrm{E}$ is maximal allowance of protein $(\mathrm{g} / \mathrm{d}), \mathrm{F}_{1}$ is $\mathrm{g}$ carbohydrate $/ 100 \mathrm{~g}$ milk, $\mathrm{F}_{2}$ is $\mathrm{g}$ carbohydrate $/ 100 \mathrm{~g}$ meat, $\mathrm{F}$ is maximal allowance of carbohydrate $(\mathrm{g} / \mathrm{d}), \mathrm{W}_{1}$ is ( $\mathrm{g}$ lipid or $\mathrm{Na}$ or $\mathrm{K}$ etc.) $/ 100 \mathrm{~g}$ milk, $\mathrm{W}_{\mathrm{z}}$ is ( $\mathrm{g}$ lipid or $\mathrm{Na}$ or $\mathrm{K}$ etc.) $/ 100 \mathrm{~g}$ meat, $\mathrm{W}$ is maximal allowance of lipid or $\mathrm{Na}$ or $\mathrm{K}$ etc. $(\mathrm{g} / \mathrm{d})$.

When the constraints are of the type $\geqslant$ (i.e. $X_{1}>\mathrm{A}$ ) it is possible to refer to the previous instances by subtracting a non-negative variable $(S U)$ which is the surplus variable

$$
X_{1}-S U=\text { A. }
$$

The 'feasible region' in the previous example (Fig. 2) is delimited by the polygon $\mathrm{E}_{5}, \mathrm{~B}_{1}$, $\mathrm{W}_{5}, \mathrm{~W}_{6}, \mathrm{~F}_{6}, \mathrm{D}_{1}, \mathrm{E}_{6}$. Sometimes the 'feasible region' can be void, as illustrated in Fig. 3. In fact the 'feasible region' delimited by the quadrilateral $A_{1}, B_{1}, C_{1}, D_{1}$ can be reduced to the triangle $A_{1}, F_{5}, F_{6}$ by a new constraint represented by the straight line $F_{3} F_{4}$. Furthermore an additional constraint, represented by the line $E_{3} E_{4}$, can delimit a second region $\left(E_{5}, B_{1}\right.$, $\mathrm{C}_{1}, \mathrm{E}_{6}$ ) which has no points in common with the previous triangle. For a further analysis of this topic see specialized texts on linear programming (Ippolito, 1974; Improta, 1975; Bronson, 1982).

The considerations developed so far for just two foods can also be applied to cases having $n$ foods. Analysing whether a feasible region exists means verifying the possibility of combining the selected foods while taking into account constraints important for the child's health (RDA) and for the feasibility of the diet (minimal and maximal helpings appropriate to the various ages).

Examining now the second question we can imagine giving the foods chosen for the diet a particular 'score' directly proportional to their nutritional quality for a particular child. 


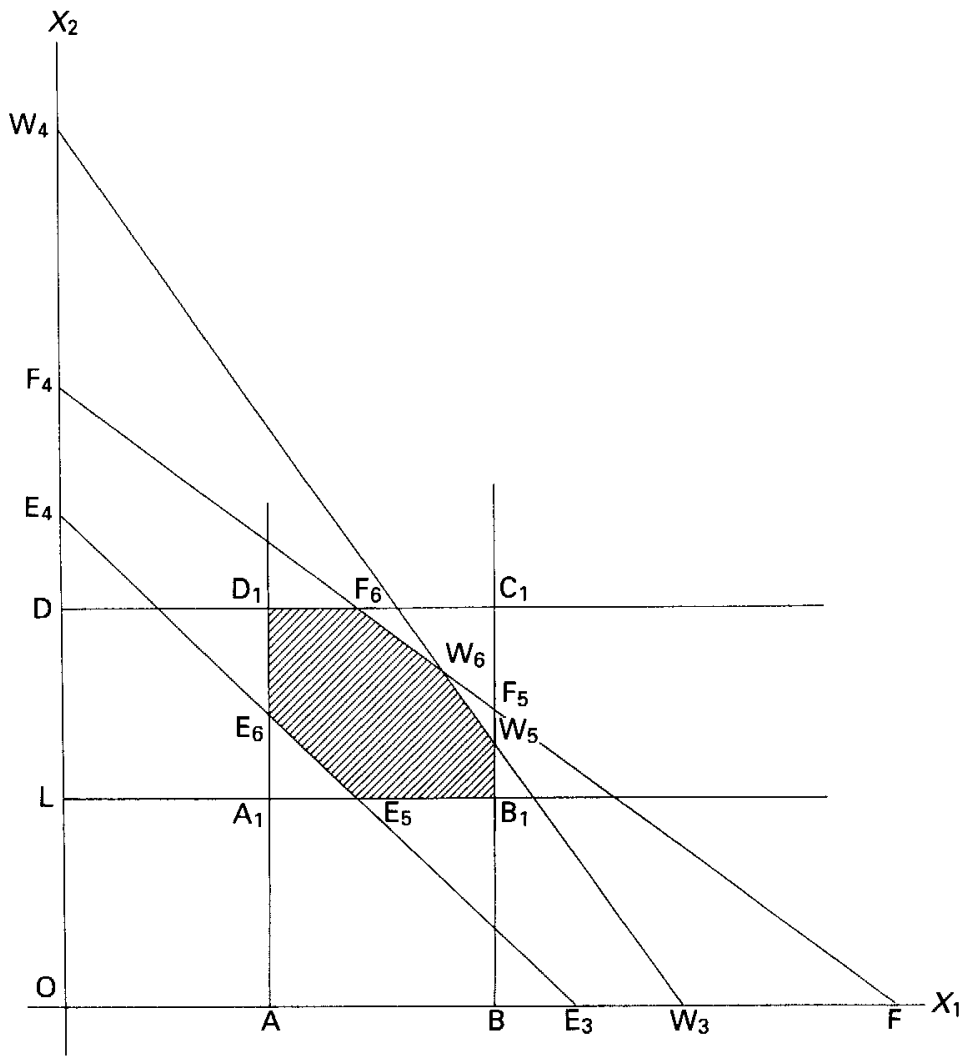

Fig. 2. The coordinates of the points located within the region delimited by the polygon $E_{5}, B_{1}, W_{5}, W_{6}, F_{6}, D_{1}$, $\mathrm{E}_{6}$, correspond, in a simple diet with two foods, to helpings satisfying a larger number of constraints than in Fig. 1 .

In the previously considered elementary diet, we can give the score $\mathrm{D}_{1}$ to the first food $\left(X_{1}\right.$ is milk) and the score $\mathrm{D}_{2}$ to the second ( $X_{2}$ is meat). While respecting the constraints, we want to find $X_{1}$ and $X_{2}$ values allowing the maximum $Z$ value in the following relationship

$$
Z=\mathrm{D}_{1} X_{1}+\mathrm{D}_{2} X_{2}
$$

which marks the quality of the diet.

The objective function (2) we want to maximize is represented on a graph by a sheaf of parallel straight lines. In order to locate the direction of this sheaf, we choose the straight line belonging to the sheaf for which $Z=0$. This straight line passes through the origin and has an angular coefficient.

$$
X_{2} / X_{1}=-\mathrm{D}_{1} / \mathrm{D}_{2}
$$

which is a quantity expressing the relationship between the preferences assigned by the pediatrician to the two foods and measured by scores $D_{1}$ and $D_{2}$. Obviously a different relationship will bring about a different position of the sheaf of parallel lines on the Cartesian plane. The line for which $Z=0$ in Fig. 1 is represented by PQ. If we consider a straight line parallel to $P Q$, for example $P_{1} Q_{1}$, the distance between these lines is proportional to $Z$ (Fig. 1). Therefore, if we want to maximize $Z$, we must shift PQ in the direction allowing $Z$ to grow without extending beyond the feasible region delimited by the pentagon $A_{1}, B_{1}, E_{5}, E_{6}, D_{1}$. It will then be necessary for the straight line parallel to $P Q$ 


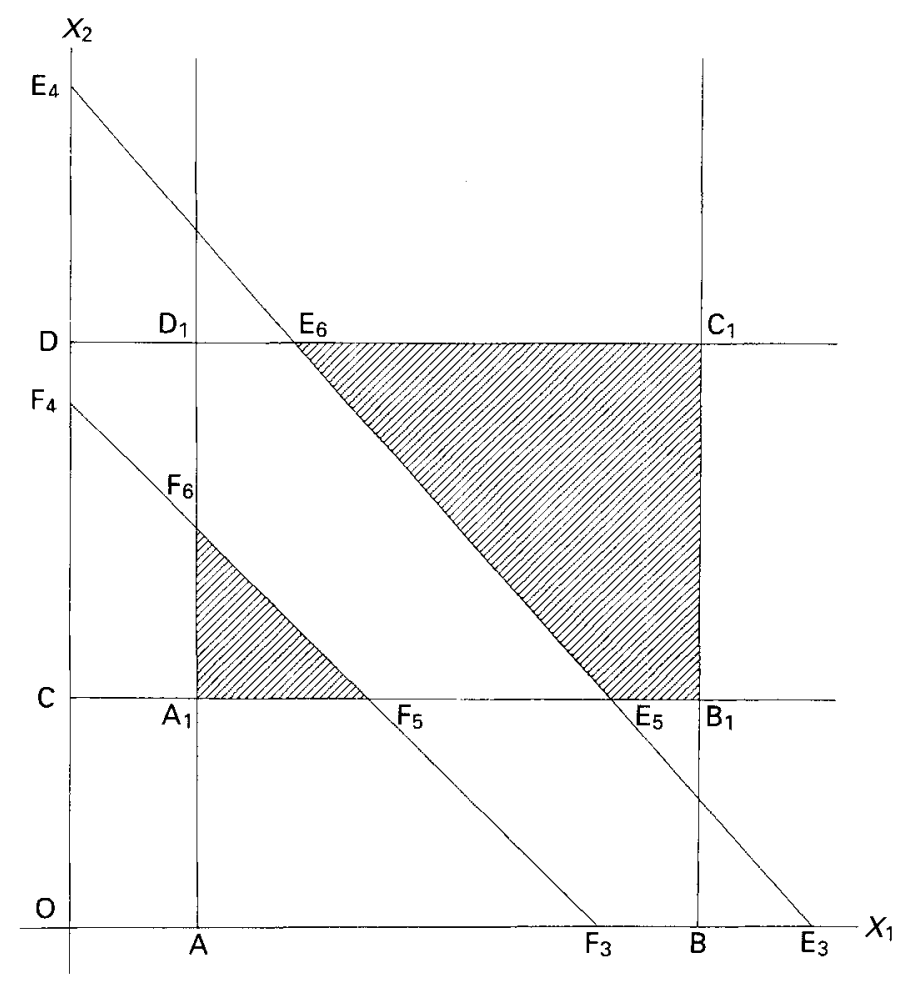

Fig. 3. The feasible region in this case is void. The constraints are so arranged that it is not possible to have helpings of the two foods satisfying all the constraints (recommended dietary allowances, etc.).

to pass through $\mathrm{E}_{6}$. The coordinates $\left(X_{1}\right.$ and $\left.X_{2}\right)$ of $\mathrm{E}_{6}$ give the solution to the problem. In fact, taking $X_{1} \mathrm{~g}$ milk and $X_{2}$ g meat, we shall obtain the maximum of the function $Z$ while respecting all the constraints. Therefore if we assign a higher score value to milk among the several available solutions we shall choose the one which contains the maximal amount of milk while staying within the given constraints.

When dealing with two variable (two foods) the geometrical representation is clear and instructive.

When examining problems with $n$ variables (foods) and $m$ constraints, analytical methods must be employed, since the geometric representation of a polyhedron delimited by hyperspaces, in which every constraint is a hyperplane, is impossible. One of the analytical methods employed is the 'simplex'. This method in our case may locate the feasible solution which, respecting the constraints, maximizes the chosen objective function and, therefore, allows the maximum amount of the foods having a higher score in the relationship (2).

Often, having selected the foods, their minimum and maximum helpings and some of the nutritional qualities (RDA, etc.) we may be faced with constraints not coherent with each other. The diet we are considering might be unrealistic because some constraints (for example, the need to guarantee the RDA of $\mathrm{Ca}$ and $\mathrm{P}$ ) are inconsistent with other constraints, such as the maximum realistic helpings of the foods we have chosen, which might have a very low content of $\mathrm{Ca}$ or $\mathrm{P}$. In these cases, the simplex method, just like the geometrical representation in the case of two foods (Fig. 3) can provide additional useful information. The latter can, among other things, help to understand which constraint 
hinders the maximization of the objective function for reasons relative to the area of the feasible solutions determined by the chosen constraints.

Some of this information is found in the analysis of the slack and surplus variables that are associated with each constraint.

A negative slack or surplus variable is associated with each constraint that contributes to the impossibility of solving the problem. If, by applying the simplex method to our example $\left(X_{1}-S U=\mathrm{A}\right)$, we found the solution to be impossible and $S U$ to be negative, we should have to deduce that in order to accommodate the other constraints, the system cannot avoid suggesting a helping of milk smaller than the one normally used. Similar considerations can be made for the slack variables. Further useful considerations can be deduced from the analysis of the shadow cost that the method provides. In effect, with each problem of linear programming there can be associated a dual problem, which derives directly from the first and which also serves to define the value we must attribute to resources used optimally. This value is defined as the shadow cost. In our case the resources are represented by the foods and by the sum of the individual components of the foods (proteins, lipids, $\mathrm{Ca}$, etc.). A shadow cost associated with each resource reflects changes in the diet's quality (that is, its objective function) based on unitary variations of the resources. We can, therefore, also say that it reflects how the objective function would change according to variations of the known terms of the constraints (RDA, minimal and maximal helpings, etc.). The shadow cost can also be helpful in modifying the constraints whenever required conditions lead to impractical cases.

The choice of studying a diet on a daily basis has led us to analyse peculiar aspects of this problem that had not been previously examined (Stiegler, 1945; Balintfy, 1964, 1974; Smith, 1959; Bassham et al. 1984). The objective of these reports was generally to define minimum cost diets for populations during extended periods (i.e. weeks) while taking into account certain nutritional standards (RDA, etc.).

Smith (1959) in fact succeeded in enhancing the acceptability of the diets by enlarging the choice of the foods and by constraining the system not to choose some foods (i.e. flour or pasta), unless they were appropriately combined with other foods (i.e. yeast, oil, etc.) normally used for their preparation or cooking. Some of these concepts seemed adaptable to our context. If in fact foods that are not very appetizing are included, the program allows for the concomitant inclusion of other foods (oil, yeast, etc.) that are normally used in their preparation. The child's acceptance of a diet in our system is also conditioned partly by how we construct the objective functions, as we shall explain later.

\section{DISCUSSION}

Now we consider further what we have defined as the 'food's score'. The crucial theoretical difficulty encountered in transferring the techniques of the simplex method to paediatric dietetics is, in our opinion, the difficulty of coherently defining the coefficients of the objective function. In transport problems the transport times are usually the coefficients of the objective function (2); in the economic field the coefficients are the cost of labour or materials, or both; this usually allows a coherent and satisfactory definition of the problem.

Could we choose, in paediatric dietetics, the cost of the foods? The maximization of the costs in order to obtain the optimal diet may not correspond to a realistic optimal solution since we cannot claim that there is a direct relationship between cost and food quality. (Advertising plays a distorting role in this regard.) On the other hand, cost reduction would be useful only when compiling diets for communities (Stiegler, 1945) or in very poor families. We therefore decided to rank foods according to the pediatrician's high or poor 


\section{Table 4. Linear programming diet breakdown*}

(Wcights are expressed in $\mathrm{g}$ and as the edible portion)

(1) $100 X_{1}+100 X_{2}+100 X_{3}+100 X_{4}+100 X_{5}+100 X_{6}+100 X_{7}+100 X_{8}+200 X_{9}+100 X_{10}+100 X_{11}+200 X_{12}$ $+10 X_{13}^{\dagger}$

(2) $X_{1}<=1 \cdot 5+$ (3) $X_{2}<=0 \cdot 1$; (4) $X_{3}<=2.8$; (5) $X_{4}<=0 \cdot 3$; (6) $X_{5}<=0 \cdot 1$; (7) $X_{6}<=0 \cdot 7$; (8) $X_{7}<=1$; (9) $X_{8}<=0.35$; (10) $X_{9}<=1 \cdot 17$; (11) $X_{10}<=1 \cdot 5$; (12) $X_{11}<=0.1$; (13) $X_{12}<=1 \cdot 5$; (14) $X_{13}<=0.5$

(15) $X_{1}>=1.2$; (16) $X_{2}>=0.05$; (17) $X_{3}>=0.8$; (18) $X_{4}>=0.05$; (19) $X_{5}>=0.05$; (20) $X_{6}>=0.3$; (21) $X_{7}>=0.4$; (22) $X_{8}>=0.1$; (23) $X_{9}>=0.72$; (24) $X_{10}>=0.97$; (25) $X_{11}>=0.05$; (26) $X_{12}>=0 \cdot 8 ;(27) X_{13}>=0 \cdot 4$

(28) $3 \cdot 2 X_{1}+7 \cdot 8 X_{3}+0 \cdot 6 X_{4}+0 \cdot 5 X_{5}+10 \cdot 8 X_{6}+0 \cdot 3 X_{7}+15 \cdot 9 X_{9}+0 \cdot 6 X_{10}+0 \cdot 5 X_{11}+8 \cdot 2 X_{12}+22 \cdot 8 X_{13}<=69$

(29) $3 \cdot 2 X_{1}+7 \cdot 8 X_{3}+0 \cdot 6 X_{4}+0 \cdot 5 X_{5}+10 \cdot 8 X_{6}+0 \cdot 3 X_{7}+15 \cdot 9 X_{9}+0 \cdot 6 X_{10}+0 \cdot 5 X_{11}+8 \cdot 2 X_{12}+22 \cdot 8 X_{13}>=55$

(30) $4 \cdot 6 X_{1}+104 \cdot 5 X_{2}+49 \cdot 7 X_{3}+58 \cdot 3 X_{4}+0 \cdot 6 X_{5}+77 \cdot 4 X_{6}+3 \cdot 4 X_{7}+0 \cdot 9 X_{9}+6 \cdot 4 X_{10}+0 \cdot 6 X_{11}+31 \cdot 5 X_{12}<=231$

(31) $4 \cdot 6 X_{1}+104 \cdot 5 X_{2}+49 \cdot 7 X_{3}+58 \cdot 3 X_{4}+0 \cdot 6 X_{5}+77 \cdot 4 X_{6}+3 \cdot 4 X_{7}+0 \cdot 9 X_{9}+6 \cdot 4 X_{10}+0 \cdot 6 X_{11}+31 \cdot 5 X_{12}>=208$

(32) $3 \cdot 7 X_{1}+1 \cdot 7 X_{3}+83 \cdot 1 X_{5}+0 \cdot 3 X_{6}+0 \cdot 2 X_{7}+100 X_{8}+1 \cdot 7 X_{4}+83 \cdot 1 X_{11}+9 \cdot 3 X_{12}+38 \cdot 1 X_{13}<=86$

(33) $3 \cdot 7 X_{1}+1 \cdot 7 X_{3}+83 \cdot 1 X_{5}+0 \cdot 3 X_{6}+0 \cdot 2 X_{7}+100 X_{8}+1 \cdot 7 X_{9}+83 \cdot 1 X_{11}+9 \cdot 3 X_{12}+38 \cdot 1 X_{13}>=78$

(34) $0.05 X_{1}+0.001 X_{2}+0.54 X_{3}+0.009 X_{4}+0.011 X_{5}+0.028 X_{6}+0.043 X_{7}+0.127 X_{3}+0.002 X_{10}+0.011 X_{11}$ $+0.036 X_{12}+2 \cdot 733 X_{13}<=1 \cdot 8$

(35) $0 \cdot 05 X_{1}+0.001 X_{2}+0 \cdot 54 X_{3}+0 \cdot 009 X_{4}+0 \cdot 011 X_{5}+0 \cdot 028 X_{6}+0 \cdot 043 X_{7}+0 \cdot 127 X_{9}+0 \cdot 002 X_{10}+0 \cdot 011 X_{11}$ $+0 \cdot 036 X_{12}+2 \cdot 733 X_{13}>=0 \cdot 6$

(36) $0 \cdot 136 X_{1}+0 \cdot 003 X_{2}+0 \cdot 21 X_{3}+0 \cdot 086 X_{4}+0 \cdot 006 X_{5}+0 \cdot 311 X_{6}+0 \cdot 076 X_{7}+0 \cdot 33 X_{9}+0 \cdot 15 X_{10}+0 \cdot 006 X_{11}$ $+0.088 X_{12}+0.323 X_{13}<=3$

(37) $0 \cdot 136 X_{1}+0 \cdot 003 X_{2}+0 \cdot 21 X_{3}+0 \cdot 086 X_{4}+0 \cdot 006 X_{5}+0 \cdot 311 X_{6}+0 \cdot 076 X_{7}+0 \cdot 33 X_{9}+0 \cdot 15 X_{10}+0 \cdot 006 X_{11}$ $+0.088 X_{12}+0.323 X_{13}>=1$

(38) $0 \cdot 124 X_{1}+0 \cdot 1 X_{3}+0 \cdot 018 X_{4}+0 \cdot 017 X_{5}+0 \cdot 017 X_{6}+0 \cdot 009 X_{7}+0 \cdot 012 X_{9}+0 \cdot 031 X_{10}+0.017 X_{11}+0 \cdot 08 X_{12}$ $+0.021 X_{13}<=0.9$

(39) $0 \cdot 124 X_{1}+0 \cdot 1 X_{3}+0 \cdot 018 X_{4}+0 \cdot 017 X_{5}+0 \cdot 017 X_{6}+0 \cdot 009 X_{7}+0 \cdot 012 X_{9}+0 \cdot 031 X_{10}+0 \cdot 017 X_{11}+0 \cdot 08 X_{12}$ $+0.021 X_{13}>=0.7$

(40) $0 \cdot 091 X_{1}+0 \cdot 097 X_{3}+0 \cdot 011 X_{4}+0.021 X_{5}+0 \cdot 165 X_{6}+0 \cdot 022 X_{7}+0 \cdot 195 X_{9}+0 \cdot 018 X_{10}+0 \cdot 021 X_{11}+0 \cdot 106 X_{12}$ $+0.178 X_{13}<=0.9$

(41) $0 \cdot 091 X_{1}+0 \cdot 097 X_{3}+0 \cdot 011 X_{4}+0.021 X_{5}+0 \cdot 165 X_{6}+0 \cdot 022 X_{7}+0 \cdot 195 X_{3}+0 \cdot 018 X_{10}+0 \cdot 021 X_{11}+0 \cdot 106 X_{12}$ $+0 \cdot 178 X_{13}>=0 \cdot 7$

* The meaning of the relationship is illustrated in Table 5.

$\uparrow$ Variable $X_{1}$ represents milk which is the first food listed in the diet described in Table 2, variable $X_{2}$ represents sugar and so on. The first line is the objective function, the others the various constraints to be respected. The simplex method will assign certain values to variable $X_{1}, X_{2}, \ldots$ so that the objective function will be maximized while all the other constraints will be respected.

$\ddagger 1=100$.

opinion of them but other methods, for example, 'preferential scores' based on acceptability of foods or better still setting priorities for different nutritional targets such as meeting iron needs, could equally be employed. The paediatrician expresses his or her opinion by assigning a "score' to each of the foods chosen.

Three possible food scores might be: 10,100 or 200 . The paediatrician may possibly leave the food score, which is normally 100 , unchanged. In this case the simplex method will give the possible solution on this basis. He may, on the other hand, decide to give preference to some foods by giving them a score of 200 or express a low opinion of other foods by reducing their score to 10 , or both. This facility for changing the coefficient of the objective function (2) is a powerful means of dietetic personalization. The simplex method, while respecting the constraints, will find in this case the maximal possible apportionment of foods with the highest scores.

\section{Case report}

We report the case of a child, Micòl F. (Table 2), who was given a hypoenergetic diet slightly deviating from normal standards (Table 3 ). The parents were concerned about the girl's lack of appetite. The patient's clinical condition was satisfactory. Having learned that 
Table 5. Detailed explanation in dietetic terms of the linear programming mathematical expressions listed in Table 4

\begin{tabular}{ll}
\hline Line & Interpretation \\
\hline $2-14$ & $\begin{array}{l}\text { Constraints reflecting maximal helpings allowed. } \\
15-27\end{array}$ \\
28 & $\begin{array}{l}\text { Constraints reflecting minimal helpings required. } \\
\text { Constraint required to avoid an excessive protein intake. }\end{array}$ \\
29 & Constraint required to ensure a minimum protein intake. \\
30 & Constraint required to avoid an excessive carbohydrate intake. \\
31 & Constraint required to ensure a minimum carbohydrate intake. \\
32 & Constraint required to avoid an excessive lipid intake. \\
33 & Constraint required to ensure a minimum lipid intake. \\
34 & Constraint required to avoid an excessive sodium intake. $\dagger$ \\
35 & Constraint required to ensure a minimum sodium intake. \\
36 & Constraint required to avoid an excessive potassium intake. \\
38 & Constraint required to ensure a minimum potassium intake. \\
39 & Constraint required to avoid an excessive calcium intake. \\
40 & Constraint required to ensure a minimum calcium intake. \\
41 & Constraint required to avoid an excessive phosphorus intake. \\
\hline
\end{tabular}

* The foods' protein content, in $100 \mathrm{~g}$ edible portion, is represented by the numerical coefficients of the variables $X_{1}, X_{2}, \ldots$. The minimal and maximal intakes of proteins, carbohydrates and lipids are calculated taking into account the need to obtain a diet having approximately $7740 \mathrm{~kJ}$, in which $0.12-0.15$ of the total energy is derived from proteins, $0.45-0.50$ from carbohydrates and $0.38-0.42$ from lipids.

$\uparrow$ The sodium, potassium, calcium and phosphorus minimal and maximal intakes that must be respected by the constraints derive from RDA.

she liked fish, (particularly sole) and pizza, we decided to give a higher score to these two foods while giving a lower one to bacon, which she disliked. Having received the informed consent of the parents, we employed the simplex method to find a better diet.

Table 4 shows the objective function and forty-nine constraints necessary to obtain a diet of $7740 \mathrm{~kJ}$ with $0 \cdot 12-0.15$ of the total energy derived from proteins, $0.45-0.50$ derived from carbohydrates and $0.38-0.42$ from lipids. Allowing $7740 \mathrm{~kJ}$ seemed an acceptable initial compromise, taking into account the girl's previously mentioned lack of appetite.

Table 5 shows what each constraint represents. (Note that foods that are present in the diet during several meals or various times during a meal (bread, oil, etc.) are actually listed as only one food in the calculations and the minimal and maximal portions are appropriately calibrated.) In our case, therefore, bread corresponds to food $X_{3}$ and maize oil to $X_{8}$. The program reflected the existence of two negative surplus variables, one being associated to the 27th constraint (ham, minimal helping) and the other one to the 39 th (minimum recommended $\mathrm{Ca}$ ). We found that the posed constraints were in fact incompatible and that it was impossible to provide a minimal helping of ham and a minimum apportionment of $\mathrm{Ca}$ while respecting the other constraints. We therefore agreed to reduce the intake of ham, since the girl disliked it. In spite of that, a negative surplus variable was still associated to the 39 th constraint (indicating that selected foods had a low content in Ca). We then analysed the shadow costs. The higher shadow costs noted were associated with the 39 th constraint (minimum recommended for $\mathrm{Ca}$ ), to the 2 nd (maximal intake of milk) and to the 27th (minimal intake of ham). Allowing a higher intake of milk and further reducing the minimal helping of ham was sufficient to render the new established constraints coherent and obtain the optimal solution illustrated in Table 6 .

Table 7 shows an analysis of this diet. The foods that are listed once in the algorithm even though eaten during several meals are redistributed interactively by the program aiming at 
C. COLAVITA AND R. D'ORSI

Table 6. The diet obtained with the simplex method

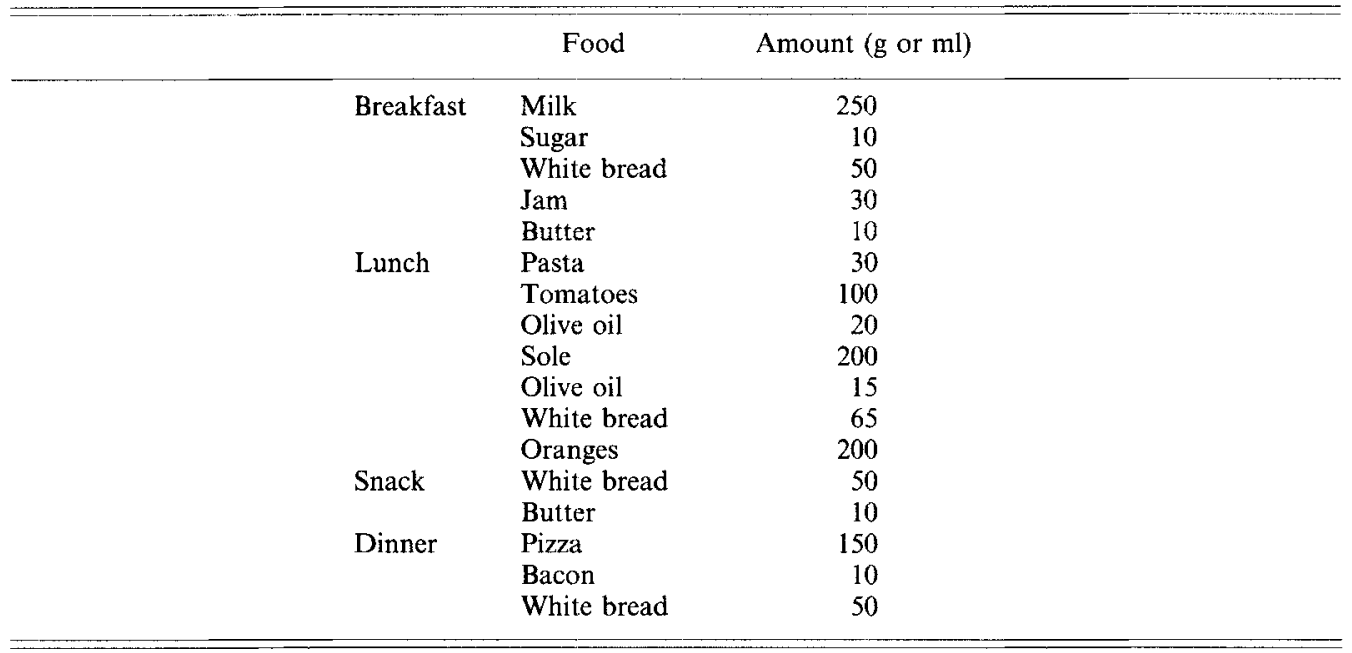

Table 7. Analysis of the diet in Table 6

(Name Micòl F, age 10 years, weight $30 \mathrm{~kg}$, height $1.35 \mathrm{~m}$, energy intake recommended $7740 \mathrm{~kJ} / \mathrm{d}$ )

\begin{tabular}{lccl}
\hline & Analysis & $\begin{array}{c}\text { Recommended dietary } \\
\text { allowances }\end{array}$ & \\
& 8000 & $9623-10460$ & OK \\
Energy (kJ) & $0 \cdot 12$ & $0 \cdot 12-0 \cdot 15$ & OK \\
Protein (\% energy) & $0 \cdot 48$ & $0 \cdot 45-0 \cdot 50$ & OK \\
Carbohydrate (\% energy) & $0 \cdot 39$ & $0 \cdot 38-0 \cdot 42$ & OK \\
Fats (\% energy) & 180 & $<300$ & OK \\
Cholesterol (mg) & 1789 & $600-1800$ & OK \\
Sodium (mg) & 1681 & $1000-3000$ & OK \\
Potassium (mg) & 727 & $700-900$ & OK \\
Calcium (mg) & 895 & $700-900$ & OK \\
Phosphorus (mg) & $7 \cdot 0$ & $9-11$ & Low \\
Iron (mg) & $0 \cdot 78$ & $0 \cdot 9-1 \cdot 0$ & Low \\
Polyunsaturated : saturated fats & 0.81 & $0 \cdot 9-1 \cdot 0$ & Low \\
Ca:P & $0 \cdot 25$ & $0 \cdot 23-0 \cdot 25$ & OK \\
Breakfast (\% energy) & 0.37 & $0 \cdot 28-0 \cdot 32$ & High \\
Lunch* (\% energy) & $0 \cdot 10$ & $0 \cdot 13-0 \cdot 15$ & Low \\
Snack (\% energy) & $0 \cdot 28$ & $0 \cdot 28-0 \cdot 32$ & OK \\
Dinner (\% energy) & & & \\
\hline \hline
\end{tabular}

* A higher energy intake was accepted as in Italy lunch is considered the main meal and it is difficult to correct this habit in a short period of time.

a better balance of energy intake between the meals. This balance seemed easier to obtain by this means rather than by a different and more complex manipulation of the constraints or of the objective function and also saved time.

In conclusion we think it is useful to employ these methods in the personalization of the child's diet. Further development of the program will of course be necessary to allow the user lacking mathematical knowledge to use the program more easily. Additional studies will be necessary to clarify the values and limits of the method. 
The authors thank Professor Ugo De Bellis, Head Physician of the S. Paolo Pediatric Division for his encouragement, and Mr Claudio De Lucia, chief manager at APG (A Programming Group) in Naples for his help in the computer field.

\section{REFERENCES}

Balintfy, J. L. (1964). Menu planning by computer. Naval Research Review 7, 255-259.

Balintfy, J. L. (1974). Mathematical models for menus. Naval Research Review 27, 1-10.

Bassham, S., Fletcher, L. R. \& Stanton, R. H. J. (1984). Dietary analysis with the aid of a microcomputer. Journal of Microcomputer Applications 7, 279-289.

Bronson, R. (1982). Operations Research: Theory and Problems. Schaum's Outline Series. New York: McGrawHill Book Company.

Fidanza, F. \& Liguori, G. (1984). Nutrizione Umana. Naples: Casa editrice Idelson.

Improta, G (1975). Elementi di Programmazione Lineare. Naples: Centro Studi di Economia applicata all'ingegneria.

Ippolito, G. (1974). Elementi di Programmazione Lineare. Naples: Liguori Edizioni S.r.1.

Luke, B. (1984). Principles of Nutrition and Diet Therapy. Boston: Little Brown and Company.

Paul, A. A. \& Southgate, D. A. T. (1978). McCance and Widdowson's The Composition of Foods, 4th ed. London: H.M. Stationery Office.

Smith, V. E. (1959). Linear programming models for the determination of palatable human diets. Journal of Farm Economics 41, 272-283.

Stiegler, G. J. (1945). The cost of subsistence. Journal of Farm Economics 27, 303-314. 